\title{
Biobank research and ethics: the problem of informed consent in Polish biobanks
}

Jakub Pawlikowski ${ }^{1,2}$, Jarosław Sak ${ }^{1}$, Krzysztof Marczewski ${ }^{3}$

\author{
1Department of Ethics and Human Philosophy, Medical University of Lublin, Poland \\ 2Institute of Rural Health, Lublin, Poland \\ ${ }^{3}$ Department of Bioethics, Anthropology and General Theory of Medicine, \\ College of Management and Public Administration, Zamosc, Poland
}

Submitted: 8 October 2010

Accepted: 18 December 2010

Arch Med Sci 2011; 7, 5: 896-901

DOI: 10.5114/aoms.2011.25568

Copyright @ 2011 Termedia \& Banach

\begin{abstract}
Introduction: The dynamic development of biobanks causes some ethical, social, and legal problems. The most discussed problems are obtaining informed consent, especially for future research, from minors and from deceased people. The aim of this article is to present the current standards held by Polish biobanks concerning obtaining a participant's informed consent in some aspects.

Material and methods: Survey was carried out by anonymous questionnaire among 59 institutions which deal with the collecting and storage of human cells and tissues in the year 2008. Twenty four filled-in copies of the questionnaires were sent back (return $=41 \%$ ).

Results: Almost every institution (92\%) obtains written consent, but a third of the surveyed institutions (29\%) do not obtain consent for the future use of the samples. The majority of the respondents (83\%) support the idea of using biological materials for research purposes of a donor who died if he did not leave any written objection to such practices and $46 \%$ of respondents stated that biobanks should obtain the consent from the already mature donor who gave their samples as a child.

Conclusions: The practice and rules for obtaining informed consent for the scientific research require improvement. The possibility to use the human materials in the future, conditions for getting access to the data, the possibility of their withdrawal from the database and using the materials and data after the death of the donor should be clearly determined when the informed consent to collect the material is obtained.
\end{abstract}

Key words: biobanks, research ethics, informed consent, genetic collection management.

\section{Introduction}

According to the definition provided by the Expert Group established by the European Commission (EC), biobanks are various types of biological sample sets, together with relevant databases [1]. They consist of private and public organizations that store biological samples for clinical purposes (genetic diagnosis, transfusion and transplantation), scientific research (e.g. testing neurodegenerative diseases, monozygotic twins and isolated populations) and criminal investigations (police biobanks) [2]. There are many hopes connected with the development of biobanks: better

\author{
Corresponding author: \\ Jakub Pawlikowski PhD \\ Department of Ethics \\ and Human Philosophy, \\ Medical University of Lublin \\ 18 Szkolna \\ 20-124 Lublin, Poland \\ E-mail: jpawlikowski@wp.pl
}


recognition of genetic and environmental factors of hereditary diseases, examination of the susceptibility to specific diseases, personalised medicine (adaptation of the treatment to the patient's individual genetic characteristics), invention of new medicines and discovery of new biomarkers.

The increasing number of biobanks in Europe and worldwide requires integration and regulations. A shortage of organisational relations between biobanks and the difficult access to some of them result in two situations: biobanks develop their own set of rules applying to the collection, storage and use of the collected material; and similar studies are done in different institutions at the same time. The collected samples are frequently not used after the research project is finished and thus they are destroyed (usually due to a shortage of funds necessary to store them); hence, their scientific potential remains unemployed [3]. Therefore, the Expert Group of the EC insists on standardising rules and practices that would facilitate sharing data and samples for scientific purposes within the territory of the European Union [1]. Last year the OECD published Guidelines on Human Biobanks and Genetic Research Databases [4]. It is also suggested that an identification code - equivalent to the International Standard Book Number (ISBN) - for the biobanks should be introduced [3]. Despite the fact that there are some biobank networks aiming at research dedicated to specific diseases (e.g. BrainNet), the most important European initiative in the field is the BBMRI (Biobanking and Biomolecular Resources Research Infrastructure) project, in cooperation with the international consortium P3G (The Public Population Project in Genomics). As a matter of fact, relatively small groups of participants are involved in many population studies in Poland [e.g. 5, 6]. Standardization of research rules in Polish biobanks and joining in international initiatives could allow them to conduct larger, multicentre studies.

The dynamic development of biobanks and genetic research causes some ethical, social and legal problems. Adequate solutions are needed in order to guarantee a balance between the innovative capacity of the scientific research and the protection of the basic rights of the participants. The Expert Group established by the EC and the OECD guidelines underline the importance of obtaining informed consent, of ensuring privacy and of respecting the right to know and not to know $[1,4]$. The risk of discrimination caused by genetic features and the possibility of commercial use of the samples (samples of human cells and tissues have become more valuable and are called 'biovalue') are among the commonly discussed issues [7-10]. However, the most discussed problem is the issue of informed consent. It is connected with the following questions: access to the collected material for scientists from other institutions; consent to use biological samples in future scientific research, using samples from donors who are now dead, from minors or donors who are unable to express any conscious consent; and the commercialization of research (e.g. gene patents). The public trust in biobanks and genetic research depends largely on whether these problems will be solved properly.

The situation of Polish biobanks and the standards of biological material storage are poorly recognised. Such a situation hinders cooperation between Polish biobanks and makes their incorporation into the European biobanks network and similar global institutions difficult. The first information about some aspects of Polish biobanks was our article published in the European Journal of Public Health [11]. There has not been a serious social debate on biobanks and genetic research in Poland yet. Some regulations of the biobanks' activity were added to the amended transplantation act of 2005: the National Centre for Tissue and Cell Banking was established and the requirement of accreditation for all institutions of the field was introduced [12]. However, it is uncertain to what extent these regulations have been implemented and there are still some issues that have not yet been introduced. These issues include consent for future research, other institution representatives' access to the data, and the problem of the sample encoding method.

In the light of all the above-mentioned issues, we decided to gain relevant data on Polish biobanks' activity and gather biobanks' managers' opinions on problems connected with obtaining informed consent. We have focused mostly on issues related to consent to future research, from minors and using biological material after the death of the donors. Studies on biobanks conducted in other European countries were based on similar assumptions [13].

\section{Material and methods}

The anonymous questionnaire was sent (by mail) to the directors of 59 institutions which deal with the collection and storage of human cells and tissues. It was sent to different types of biobanks: umbilical cord blood banks (9), Regional Centres for Blood Donation and Haemotherapy (22), hospital blood and tissue banks (10), molecular diagnosis laboratories associated with The Polish Society of Human Genetics (9) and tissue banks associated with the Poltransplant network (9). There is no official Polish database containing all biobanks, so the addresses were found on the Internet on the following websites: the National Centre for Tissue 
and Cell Banking (www.kcbtik.pl), Poltransplant (www.poltransplant.org.pl), the Polish Society of Human Genetics (www.ibb.waw.pl), the National Blood Centre (www.nck.gov.pl) and other websites connected with healthcare and genetic research in Poland. Together with the questionnaires, stamps and envelopes (with a return address) were sent. The survey was conducted from March to June 2008.

The questions in the questionnaire focused mainly on the following issues: informed consent (the way the information is provided, obtaining consent to use the biological material in the future), respect for privacy (the anonymity of the stored data, the method of coding, accessibility) and observance of the right to know and not to know. The respondents were also asked to suggest the best solution to a situation where the research institution desires to use the biological samples collected from a donor who has already died or from a child who has already become an adult.

\section{Results}

Twenty-four filled-in copies of the questionnaires out of 59 sent to biobanks were sent back (return $=41 \%$ ). All received questionnaires were filled in completely. The level of return was lowered by wellknown causes (outdated addresses, liquidation of biobank; it relates to $18 \%$ of non-respondents) and could have been lowered by unknown factors, such as reluctance to cooperate or fear of revealing the data. Some of the institutions voluntarily revealed the data enabling their identification, but in the majority of cases it was not known because the questionnaire was anonymous.

Written consent for scientific use of materials is obtained in almost every institution ( $92 \%, n=22)$; the rest of them obtain oral consent. However, only in $54 \%$ of the requested biobanks $(n=13)$ is it possible for a donor to talk to an expert before donating, and the information leaflets for the participants are available in $29 \%$ of the institutions $(n=7)$. Almost one third of the surveyed biobanks $(29 \%, n=7)$ do not acquire consent for future use of the samples. A quarter of the respondents $(25 \%$, $n=6)$ stated that a patient does not have the right not to know the test results.

The respondents were also asked about scientific use of biological material from a donor who is no longer alive and from an adult whose samples were taken when he was a child, with the consent of his parents. In the first case, the majority of the respondents ( $83 \%, n=20)$ supported the idea of using the samples of the donor who has died if he did not leave any written objection to such practices before his death. In the second case, the respondents' opinions were very diverse: $46 \%$ $(n=11)$ of them stated that written or at least electronic consent from the already mature donor should be obtained, $38 \%(n=9)$ indicated the possibility of using the material on the basis of the previous parents' consent, and the rest of the respondents indicated that the donor should be informed in writing and in the case of lack of his or her objection the sample could be used.

\section{Discussion}

The most frequently discussed ethical issue associated with biobanks' activity is the method of providing information and obtaining informed consent for scientific research, especially for future scientific research. The practice of obtaining written consent is observed in $92 \%$ of the surveyed institutions, but a serious problem is that $8 \%$ of biobanks obtain only oral consent (an oral form is incorrect in this case). Other European countries have a similar problem [13]. The results of our survey also indicate that the way of providing information in many Polish biobanks does not meet the international requirements (the lack of written information and the lack of the possibility to consult an expert). The Expert Group of the EC and the OECD recommend obtaining written consent from a donor during a direct discussion, preceded by a reading of the written informational leaflet $[1,4]$. This procedure results from the fact that information expressed in speech is more direct and allows additional explanations to be given; however, it can also be incomplete or it can be used to exert an influence on the interlocutor. Printed information, on the other hand, even if it can be more complete, gives no guarantee that it is well understood. Additionally, it should be mentioned that according to the EU directive (95/46/EC), individuals who donate samples for the research should not only understand what collecting the material involves and what kind of risk is related to it but should also be provided with information on the purposes of the samples' usage [14]. Similarly, the European Biomedical Convention (Convention for the Protection of Human Rights and Dignity of the Human Being with regard to the Application of Biology and Medicine: Convention on Human Rights and Biomedicine) emphasises in article no. 22 that human tissues as well as cells isolated from the human organism can only be used for purposes they were collected for and within the area of use defined by the donor's consent.

An unfavourable phenomenon is that quite a high percentage (28\%) of the surveyed institutions do not obtain consent to use samples in future scientific research. It hinders conducting research on the samples and it shows a lack of awareness of the fact that the samples could be used some other time or the lack of far-reaching plans for operation. However, a survey conducted 
in six Western European countries demonstrated that consent for future scientific use is rarely obtained in biobanks in those countries as well [13].

Obtaining donor consent for the future use of samples in scientific research provokes the biggest disputes and doubts. The restrictive attitude to the informed consent requirements would demand frequent asking about the use of previously collected data, which could prove to be very disturbing and could discourage researchers from conducting studies and donors from participating in them. Because of that, different possible solutions to this problem were suggested. For example, the International Bioethics Committee of UNESCO, WHO and some authors suggest a blanket consent to possible future scientific research [7, 15, 16], others a presumed consent with opt-out [1719]. Some suggest not demanding distinct consent before each study if the law guarantees access to the data only to the researchers, the samples are anonymous and the rules of collecting and storing the tissues are under social control [20]. However, it seems that such a form does not meet the conditions of informed consent, because it does not protect the donors' interests [21]. CIOMS (the Council for International Organizations of Medical Sciences) believes that in cases of minimal risk the ethical commission can waive the requirement of obtaining informed consent for successive research (it is the so-called waived consent) [22]. As a matter of fact, in public opinion polls a significant percentage of the respondents supported the requirement of obtaining consent before each successive study conducted on the samples - e.g. it is $22 \%$ in Sweden, $29 \%$ in the US and over $50 \%$ in the UK [19, 23, 24]. Caulfield et al. suggested an authorisation model that would make it possible to define what usage of the samples the donors do not accept or in what circumstances they demand to be asked to express distinct consent (e.g. in the case of a study that has clinical significance for the donor or when the research is to be commercially used) [18] On the other hand, the First Genetic Trust, an American biotechnological concern, worked out a procedure of dynamic consent by sending the donors electronic information on the use of their samples before each successive study [25]. The European Society of Human Genetics suggested diversifying the rules of informed consent: if an existing collection consists of encoded samples with no possibility of identifying the donor (the so-called "anonymised collection"), it is allowed to use them without obtaining new consent. However, if identification of the donor is possible ("identifiable collection"), the researchers should apply to obtain consent and if it appears to be impossible, the decision should be made by the bioethics committee. Consent is always required in the case of creating new collections of biological material [26].

An essential issue connected with informed consent in genetic tests is the right not to know. It results from the domination of prognostic genetic tests that allow one to detect rare monogenic diseases for which there is a lack of an effective method of treatment and the awareness of being ill is a psychological burden for the patient. The survey reveals the disturbing fact that a considerable percentage of Polish institutions (38\%) dealing with genetic tests do not respect the patient's right not to know. It might be a result of a low level of knowledge of this law among Polish society as well as among the workers and managers of the biobanks. Respecting the law can be especially important in the case of children, e.g. in the case of Huntington disease it can be stated that knowledge about some threats related to disease progression strongly limits the development of the sick children [27].

The cases of the use of samples recovered from a donor who has died and from an adult whose samples were taken when he was a child with the consent of his parents are discussed in ethical literature [28, 29]. The majority of countries have approved the standard of presumed consent in cases of samples from a donor who has died. That is consistent with the Expert Group of EC recommendations [1]. In the case of samples collected from children, the solutions vary, e.g. in France there is a standard of providing information to now mature donors about the use of samples in a study [30]. Polish respondents' opinions are generally consistent with the Expert Group of EC recommendations. It should also be mentioned that in the case of research on children, the risk of trauma increases and obtaining informed consent is more difficult. It seems fair to qualify for such research only children over 7 years old when expected improvements in their health will be significant and can be obtained only through scientific research [31].

It is becoming apparent that the amendment of the Polish Transplantation Act from 2005 does not sufficiently regulate Polish biobanks' activity and does not lead to its integration. It should be stated that the chance to use the samples in the future, conditions for getting access to the data, the possibility of their withdrawal from the database and using the materials and data after the death should be clearly determined in a preliminary contract or when consent to collect the material is obtained. It should favour an increase in public trust in biobanks and minimise the risk of potential conflicts.

There are some limitations of our study. The return rate is low (41\%) and it is possible that not 
all biobanks were included because there is no official Polish database for all biobanks. However, these results allow us to reach some important conclusions.

In conclusion, some rules in the process of obtaining informed consent in Polish biobanks should be improved: obtaining consent for the future use of samples in scientific research, the possibility to talk with an expert before donating, respecting the right not to know and the requirement of obtaining consent in a written form should be obeyed in all institutions. Biological materials of deceased persons should be used for research purposes if a donor who died did not leave any written objection to such practices.

The current biobanks' procedures in obtaining informed consent do not differ to a relevant degree from procedures applied in Western European countries, and many Polish organisations can cooperate with foreign institutions.

The possibility to use human materials in the future, conditions for getting access to the data, the possibility of their withdrawal from the database and using the materials and data after the death of the donor should be clearly determined when the consent is obtained and the sample is given. The consistency and transparency of biobanks' activity rules should promote public trust and minimise the possibility of conflicts between donors and biobanks.

\section{Acknowledgments}

The research was funded by the Ministry of Science and Higher Education (Project No. DS 507, duration of the project: 2007-2009).

\section{References}

1. McNelly E, Combon-Thomsen A. 25 Recommendations on the ethical, legal and social implications of genetic testing. Brussels, 2004. Available at: http://ec.europa.eu/research/ conferences/2004/genetic/pdf/recommendations_en.pdf (4 October 2010).

2. Molnar MJ, Bencsik P. Establishing a NeurologicalPsychiatric Biobank: banking, informatics, ethics. Cell Immunol 2006; 244: 101-4.

3. Kauffman F, Cambon-Thomsen A. Tracing biological collections: between books and clinical trials. JAMA 2008 299: 2316-8.

4. OECD. Guidelines on Human Biobanks and Genetic Research Databases. 2009 http://www.oecd.org/ document/12/0,3343,en_2649_34537_40302092_1_1_1_1, 00\&\&en-USS 01DBC.html (4 October 2010).

5. Sakowicz A, Fendler W, Lelonek M, Pietrucha T. Genetic variability and the risk of myocardial infarction in Poles under 45 years of age. Arch Med Sci 2010; 6: 160-7.

6. Bitner A, Kalinka J. IL-beta, IL-6 promoter, TNF-alpha; promoter and IL-1RA gene polymorphisms and the risk of preterm delivery due to preterm premature rupture of membranes in a population of Polish women. Arch Med Sci 2010; 6: 552-7.
7. Hansson S. The Ethics of Biobanks. Cambridge Quarterly of Healthcare Ethics 2004; 13: 319-26.

8. Horrobin DF. Innovation in the pharmaceutical industry. J Royal Soc Med 2000; 93: 341-5.

9. Shicle D. The consent problem within DNA biobanks. Stud Hist Philos Biol Biomed Sci 2003; 37: 503-19.

10. Jonsen A, Siegler M, Winslade WJ. Clinical ethics. A practical approach to ethical decisions in clinical medicine. $6^{\text {th }}$ ed. McGraw-Hill, 2006.

11. Pawlikowski J, Sak J, Marczewski K. The analysis of the ethical, organizational and legal aspects of Polish biobanks activity. Eur J Public Health 2010; 20: 707-10.

12. The Cell, Tissue and Organ Recovery, Storage and Transplantation Act of July 1 15t, 2005. The Official Journal of Acts 'Dziennik Ustaw' 05.169.1411. (Ustawa o pobieraniu, przechowywaniu i przeszczepianiu komórek, tkanek i narządów z dn. 1 lipca 2005. Dz.U.05.169.1411).

13. Hirtzlin I, Dubreuil Ch, Préaubert N, et al. An empirical survey on biobanking of human genetic material and data in six EU countries. Eur J Hum Genet 2003; 11: 475-88.

14. Directive 95/46/EC of The European Parliament and of The Council of 24 Oct 1995 on the protection of individuals with regard to the processing of personal data and on the free movement of such data. Official Journal of the European Communities 23.11.95, No L 281/31.

15. UNESCO, 2002. Human genetic data: preliminary study by the IBC on its collection, processing, storage and use. Paris, UNESCO. Available at: http://portal.unesco.org/ shs/en/files/2138/10563744931Rapfinal_gendata_en.pdf/ Rapfinal_gendata_en.pdf (4 April 2009).

16. WHO. Proposed international guidelines on ethical issues in medical genetics and genetic services. Report of a WHO meeting on ethical issues in medical genetic. Geneva, 1998. Available at: http://www.who.int/genomics/ publications/en/ethicalguidelines1998.pdf (4 April 2009).

17. Corrigan OP, Williams-Jones B. Pharmacogenetics, the bioethical problem of DNA investment banking. Stud Hist Philos Biol Biomed Sci 2006; 37: 550-65.

18. Caulfield T, Upshur REG, Daar A. DNA databanks and consent: a suggested policy option involving an authorization model. BMC Med Ethics 2003; 4: 1.

19. Wendler D, Emanuel E. The debate over research on stored biological samples: what do sources think? Arch Intern Med 2002; 162: 1457-62

20. Hansson MG. Combining efficiency and concerns about integrity when using human biobanks. Stud Hist Philos Biol Biomed Sci 2006; 37: 520-32.

21. Deschênes C, Cardinal G, Knoppers BM, Glass K. Human genetic research, DNA banking and consent: a question of 'form'? Clin Genet 2001; 59: 221-39.

22. CIOMS (Council for International Organizations of Medical Sciences), 2002. International ethical guidelines for biomedical research involving human subjects. CIOMS, Geneva.

23. Stagmary B, Asplund K. Informed consent for genetic research on blood stored for more than a decade: a population based study. BMJ 2002; 325: 634-5.

24. Human Genetics Commission. People's Panel. Public attitudes to human genetic information: People's Panel quantitative study conducted for the Human Genetics Commission. London, 2001. Available at: http://www.hgc. gov.uk/UploadDocs/DocPub/Document/morigeneticattitu des.pdf (4 April 2009).

25. First Genetic Trust, 2002. Available at: http://www. firstgenetic.net/products_icf.html (4 October 2010).

26. ESHG (European Society of Human Genetics). Recommendations of the European Society of Human Genetics. 
Data storage and DNA banking for biomedical research: technical, social and ethical issues. Eur J Hum Genet 2003; 11 (Suppl 2): 8-10.

27. Sobel S, Cowan DB. Impact of genetic testing for Huntington disease on the family as a system. Am J Med Gen 2000; 62: 121-7.

28. Skene L. Ownership of human tissue and the law. Nat Rev Genet 2002; 3: 145-8.

29. Lawrence SC. Beyond the grave. In: Stored tissue samples: ethical, legal, and public policy implications. Weir RF (ed.). lowa City, University of lowa Press, 1998.

30. Rial-Sebbag E. From medical biobanks to research tools: new opportunity offered from the French legal perspective. Translationale medicine and public health policy: lessons from biobanks ethical, legal, Social Issues (ELSI). Brocher Foundation workshop, Geneva, 5-7 Dec 2007 (oral presentation).

31. Hertz DC, Fanos JH, Reill PR. Genetic testing for children and adolescents: who decides? JAMA 1994; 272: 875-81. 